\title{
60KDa chaperonin (HSP60) is over-expressed during colorectal carcinogenesis
}

\author{
F. Cappello, M. Bellafiore, A. Palma, S. David, V. Marcianò, T. Bartolotta," C. Sciumè," \\ G. Modica, ${ }^{*}$ F. Farina, G. Zummo, F. Bucchieri \\ Human Anatomy Section, Department of Experimental Medicine, University of Palermo (Italy); *General \\ and Thoracic Surgery, Department of Surgical and Oncological Sciences, University of Palermo, Italy
}

(C)2003, European Journal of Histochemistry

The aim of the present study was to evaluate the expression of the heat shock protein 60 (HSP60), a mitochondrial matrix-associated protein belonging to the chaperonin family, in colorectal adenomas and cancers, comparing them to normal colonic tissues and hyperplastic polyps. We performed both immunohistochemistry and Western blot analysis for HSP60. Immunohistochemistry resulted positive in all tubular adenomas and infiltrating adenocarcinomas. By contrast, normal tissues and hyperplastic polyps were negative. Quantitative analysis showed that tubular adenomas with different levels of dysplasia did not present statistical differences concerning HSP60 positivity. In addition, carcinomas always showed the highest expression. Western blot analysis confirmed these observations. These data suggest that HSP60 over-expression is an early event in carcinogenesis. We suspect that HSP60 plays a different role in colorectal carcinogenesis with respect to that in normal cells, which foresees its possible use as diagnostic and prognostic tools.

Key words: pre-neoplastic lesions; dysplasia; heat shock proteins

Correspondence: Francesco Cappello, M.D., via alla Falconara 120, 90136, Palermo, Italy. Phone/Fax: international +39-091-6553518. E-mail: francapp@hotmail.com

Paper accepted on June 17, 2002

European Journal of Histochemistry 2003; vol. 47 issue 2 [Apr-Jun]:105-110
C olonic epithelium is bathed in a lifelong effluent of breakdown products of digestion, among which are carcinogens. The exposure of lining cells to carcinogens may determine the arise of mutations, the first step towards cancer (Tomlinson et al., 1997). It is now accepted that colon cancer starts as a flat or polypoid benign epithelial lesion that enlarges to become an invasive cancer. Nevertheless, not all-colorectal polyps are pre-neoplastic lesions (Rosai, 1996).

Hyperplastic polyps and tubular adenomas are two of the most commonly found colorectal polyps. It has been demonstrated that the malignant potential of these two lesions is quite different; the former does not progress towards cancer, whereas the tubular adenomas often degenerate into malignant tumours (Cooper, 1999). Moreover, adenomas of the large bowel are very common pre-neoplastic lesions (Nitta et al., 1993), and their prognosis is related to the size and type of adenoma as well as to the presence and grade of dysplasia. Indeed, an untreated tubular adenoma has a high probability of progressing towards cancer (Correa, 1978).

$60 \mathrm{kDa}$ heat shock protein ( HSP60) belongs to the chaperonin family and is involved in many cellular functions, i.e. folding and assembling of polypeptide chains in mitochondria (Hartl et al., 1994). Recently, it has been highlighted that carcinomas show a higher expression of some HSPs, such as HSP27 and HSP70, than normal or dysplastic tissues (Ehrenfried et al., 1995; Melis and White, 1999). Moreover, a possible role of these proteins in the regulation of tumor cell proliferation has been suggested, foreseeing their possible employment as prognostic factors (Ehrenfried et al., 1995).

The aim of the present study was to evaluate the presence and expression of HSP60 in hyperplastic polyps, tubular adenomas (with different levels of dysplasia) and infiltrating carcinomas of the large bowel, in order to investigate the role of this chaperonin in colorectal carcinogenesis. 


\section{Materials and Methods Specimen collection}

Hyperplastic polyps and tubular adenomas were collected at the Department of Surgical and Oncological Sciences of the University of Palermo, Italy. Diagnoses were performed at the Institute of Pathological Anatomy of the University of Palermo. The tissues were formalin-fixed and paraffin-embedded for routine diagnosis and immunohistochemistry; moreover, a small part of each biopsy was frozen for Western blot analysis. We selected 10 hyperplastic polyps (HP), 20 tubular adenomas, 10 invasive adenocarcinomas (IA) and 10 specimens from normal colonic mucosa (NC). We divided the tubular adenomas into two groups, according to their level of dysplasia; 10 adenomas with mildintermediate (MIA) and 10 adenomas with intermediate-severe (ISA) grade of dysplasia were selected. All selected invasive adenocarcinomas were of intermediate grade.

\section{Immunohistochemistry and quantitative analysis}

Immunostaining with the avidin-biotin complex method (LSAB2 kit peroxidase, DAKO Cat. No K0677) was performed, using primary antibodies against HSP60 (monoclonal mouse, 1:500, SIGMA, Cat. No. H4149, 1:500) and isotypematched control, on six-micra formalin-fixed, paraffin embedded sections. Aminoethylcarbazole (DAK0, Cat. No. K0677) was used as develop chromogen. Counterstaining was performed with aqueous hematoxylin (DAK0, Cat. No. S2020).

The immunoexpression of HSP60 in the epithelium of the biopsies was quantified by computerassisted image analysis (Colourvision 1.7.6, Improvision, Coventry, UK). For each biopsy, the entire intact epithelium in two non-serial sections was systematically assessed on the basis of red, green and blue (RGB) colour balance. At the beginning of each session, the image analysis system was standardised using the same section of tissue stained for the HSP60 to ensure the reproducibility of analysis. The digitised image of the standard section was used to interactively sample an example of the positive staining and the system was then allowed to select all the pixels of the same RGB colour balance (i.e., positive staining) within the image. The area of the epithelium was then delineated interactively and the percentage of positive staining within the epithelium was determined; the colour balance and percent staining value was recorded for future sessions. At the beginning of each subsequent session, the image analyser was calibrated using this section and adjusted to within $\pm 5 \%$ of the original pixel reading. Once the system had been set up using the 'standard' slide, the test sections were analysed, using the same parameters. An observer who was unaware of the clinical group from which the biopsy specimen was derived, performed measurements of HSP60 expression. Each tissue section was analysed on two separate occasions by the same observer; the data were analysed using the Mann Whitney $U$ test; $p<0.05$ was considered significant.

\section{Western Blot analysis}

$20 \mathrm{mg}$ of total cell extracts to each lane and a protein marker (Kaleidoscope pre-stained standard, Bio-Rad, Cat. No 1610324) were separated by electrophoresis on denaturing $10 \%$ polyacrylamide slab gels (SDS-PAGE) and transferred to nitrocellulose membranes (Nitrocell Paper, BioRad, Cat. No 1620115). After 1 hour at room temperature with a blocking buffer ( $5 \%$ low-fat dried milk in TBST: $50 \mathrm{mM}$ Tris- $\mathrm{HCl} \mathrm{pH} \mathrm{7.5,} 150 \mathrm{mM}$ $\mathrm{NaCl}, 0.1 \%$ Tween-20) under gentle shaking, the membranes were incubated with anti-HSP60 primary antibody (1:500) overnight at $4{ }^{\circ} \mathrm{C}$. After washing, the membranes were incubated with HRPconjugated secondary antibody (anti-mouse, Pierce, 1:5000, Cat. No 31432) for 1 hour at room temperature with shaking, and the specific binding was detected using a chemiluminescent substrate (SuperSignal West Pico Chemiluminescent Substrate, Pierce, Cat. No 34080) for autoradiography.

\section{Results}

HP were negative at immunohistochemistry (Figure 1c, d), as were NC (Figure $1 a, b$ ); only occasional positive cells were found in both epithelium and stroma. MIA were characterised by positive cellular elements; in particular, a moderatestrong cytoplasmic positivity was localised in almost all dysplastic cells, while normal epithelial cells present at the margin of dysplasia were negative (Figure $1 \mathrm{e}, \mathrm{f}$ ). Analogously to MIA, ISA showed a moderate-strong positivity of colonic dysplastic cells (not shown); in both cases, lamina propria showed scarce positive cells. Finally, IA presented islets of strongly positive neoplastic cells with a negligible positivity in the interposed stroma 

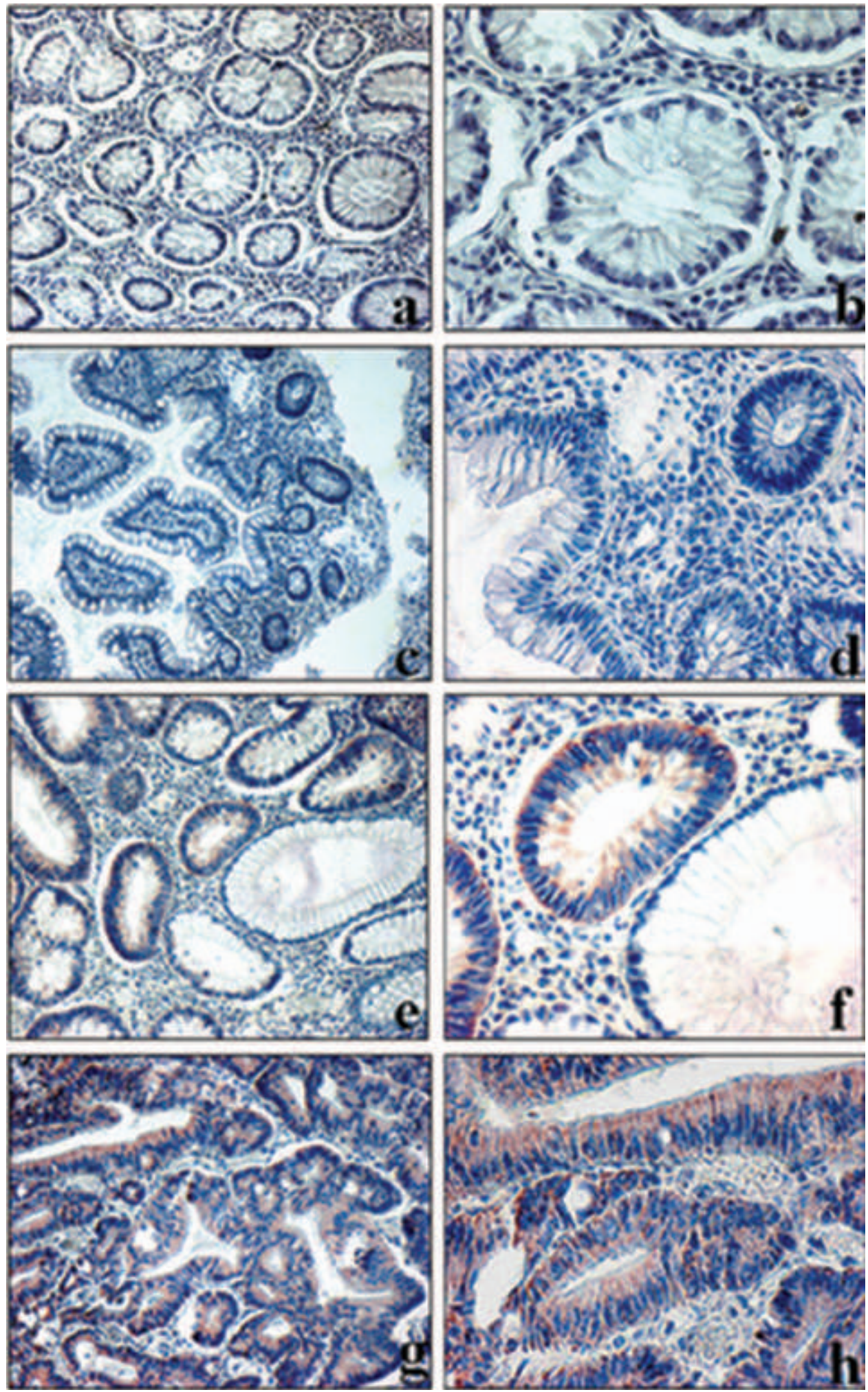

Figure 1. Representative immunostaining results for HSP60 in a normal colonic mucosa (NC) (a: 10X; b: 25X); a hyperplastic polyp (HP) (c: 10X; d: 25X); a tubular adenoma with mild-intermediate displasia (MIA); in the lower right corner, an islet of NC showing absence of HSP60 (e: 10X; f: 25X), and an infiltrating adenocarcinoma (IA) (g: 10X; h: 25X). The tubular adenomas with intermediatesevere grade of dysplasia (ISA) did not show any differences in comparison with MIA. 
(Figure 1g, h).

Quantitative analysis data showed the absence of significant differences comparing MIA and ISA [\% epithelial staining, (range)]: [53 (46-66) vs. 55 $(46-69),(p>0.05)]$. The absence of positivity in NC and HP did not permit any comparative evaluation. Moreover, the alteration of morphological architecture in IA (islets of tumor with interposed stroma) did not permit comparison of its HSP60 expression with that of the other conditions. However, HSP60 was always very high in tumoral tissues [80 (6995)].

Western blot analysis confirmed these observations; HSP60 in NC and HP was below the detectable threshold, while MIA, ISA and IA had a variable positivity, carcinomas always showing the highest positivity (Figure 2).

\section{Discussion}

Colon cancer is probably the most studied model of carcinogenesis. Many investigations have focused on its pathogenesis, defining the multi-step evolution theory derived from both epidemiological and morphologic studies. Many genetic models for colorectal carcinogenesis have been presented (Fearon and Vogelstein, 1990), pointing out that mutational activation of oncogenes is necessary in at least four or five genes. Moreover, it is also noted that accumulation of genetic mutations is responsible for determining the biologic properties of the tumor. The clinical applications of molecular genetic advances have been evolving in the last few years and most of them can now be used to determine the biologic potential of colorectal carcinomas (Iino et al., 1994; Griffin et al., 1987).

Evidence indicating a role of HSPs in tumorigenesis is increasing. HSPs are a group of proteins with a variety of functions, whose expression increases following a number of environmental and pathophysiologic stimuli. The relationship between HSP72 and HSP73 and p53 expression, clinicopathologic factors and prognosis in colorectal carcinoma has been well documented by Sun et al. (1997), who found a correlation between these HSPs and cytoplasmic p53 expression but not with nuclear p53 expression, sex, age, tumor site, Duke's stage, growth pattern or differentiation. Moreover, Lazaris et al. (1995) showed that $77.3 \%$ of 128 colorectal carcinomas were HSP70-positive and HSP70 expression was significantly correlated with low tumoral differentiation. In addition, HSP27

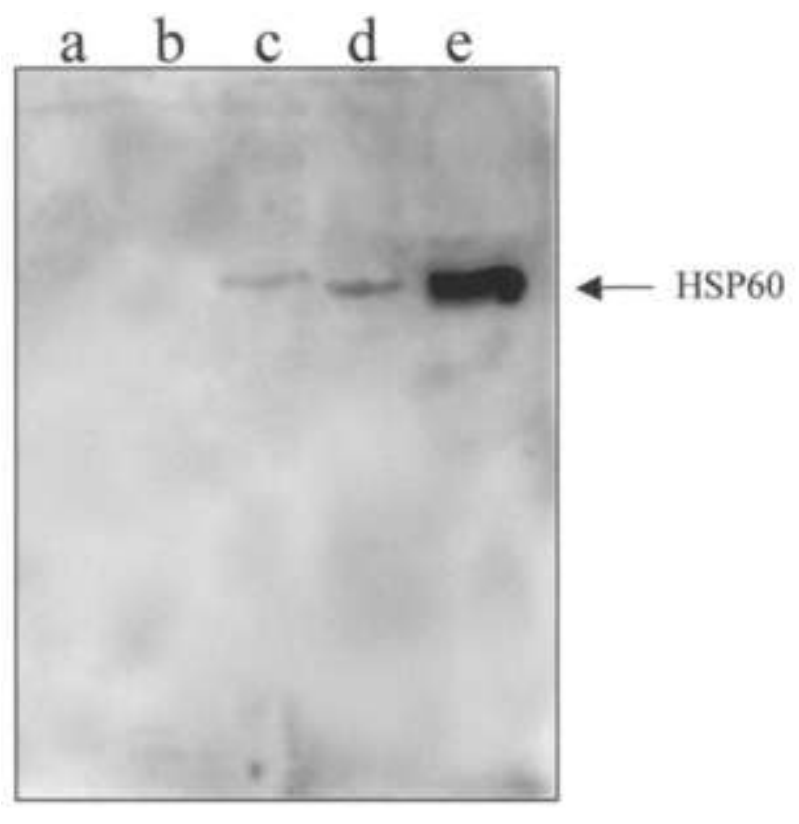

Figure 2. Representative Western blotting result for HSP60 in an NC (a); a HP (b); a MIA (c); an ISA (d); an IA (e). In NC and HP, HSP60 was below the detectable threshold, while MIA and ISA showed a similar expression of this protein. HSP60 always presented the highest expression in IA.

over-expression was found to be an essential step to establish the resistance of human colorectal cancer cell lines to cell death induced by anticancer drugs (Garrido et al., 1997).

Recently, following the detection of high titers of HSP60 in 3 of 29 patients with pre-malignant lesions of the oral cavity (Castelli et al., 2001), a role for HSP60 in carcinogenesis has been suggested. Moreover, HSP60 was expressed on the plasma membrane of human pancreatic carcinoma cells (Vendetti et al., 2000) and this expression may be of prognostic and diagnostic significance. The expression of HSP60 was different during tongue carcinogenesis. Indeed, dysplastic lesions of tongue stained strongly for HSP60, while squamous cell carcinomas were negative for this marker (Ito et al., 1998). To our knowledge, there are no studies focusing on in vivo HSP60 expression during colorectal carcinogenesis, if one excludes the observation that HSP60 was found to be increased in 13 colonic polyps (Melis and White, 1999), using two dimensional gel analysis, without any differentiation among the types of polyps.

In the present study, we demonstrated the overexpression of HSP60 in tubular adenomas of the large bowel as well as in colorectal cancers. HSP60 
positivity was localized in the cytoplasm of dysplastic cells of tubular adenomas. This over-expression was independent of dysplasia grades of adenomas, as shown by immunohistochemistry, and confirmed by both quantitative and Western blot analysis. These data suggest that HSP60 accumulation occurs early during colonic carcinogenesis.

HSP60 has an important role in the protection of prokaryotic and eukaryotic cells during environmental stresses, regulating cell differentiation and proliferation (Zhang et al., 2001). Since HSP60 is essential for cell survival, its over-expression in preneoplastic lesions and cancer could be due to an increase of its demand by proliferating tumoral cells. Alternatively, HSP60 over-expression in dysplastic and neoplastic epithelial cells could be due to a mutated form of HSP60 that has lost its functional roles and accumulates in cytoplasm.

In conclusion, in this study we demonstrated the over-expression of HSP60 during colorectal carcinogenesis. Its negativity in hyperplastic polyps is further confirmation that these tumors do not have any malignant potential. Studies on the cytoplasmic immunolocalisation of this protein may permit an understanding of the reason for its over-expression in pre-neoplastic and neoplastic lesions. Finally, the localisation of the HSP60 gene in the human genome, which is still unknown, will permit the study of its possible mutations during the carcinogenetic steps.

\section{Acknowledgements}

This research was funded by "Finanziamento Progetto Giovani Ricercatori anno 1999". We are grateful to Mr. S. Gentile, Dr. M. Salvato and Dr. M. Campione for their technical support.

\section{References}

Baker SJ, Fearon ER, Nigro JM, Hamilton SR, Preisinger AJ, Jessup $\mathrm{JM}$, et al. Chromosome 17 deletions and p53 gene mutations in colorectal carcinomas. Science 1989;244:217-21.

Castelli M, Cianfriglia F, Manieri A, Palma L, Pezzuto RW, Falasca G, et al. Anti-p53 and anti-heat shock proteins antibodies in patients with malignant or pre-neoplastic lesions of the oral cavity. Anticancer Res 2001;21:753-8.

Cooper HS. Intestinal neoplasms. In: Sternberg SS, Ed. Diagnostic Surgical Pathology. Philadelphia: Lippincott Williams \& Wilkins; 1999. p. 1413-36.

Correa P. Epidemiology of polyps in cancer. In: Morson BC, Ed. Pathogenesis of colorectal cancer. Philadelphia: WB Saunders; 1978. p. 126-52.

Ehrenfried JA, Herron BE, Townsend CM Jr, Evers CM Jr. Heat shock proteins are differentially expressed in human gastrointestinal cancers. Surg Oncol 1995;4:197-203.

Fearon ER, Vogelstein B. A genetic model for colorectal tumorigenesis. Cell 1990;61:759-67.

Garrido C, Ottavi P, Fromentin A, Hammann A, Arrigo AP, Chauffert B, et al. HSP27 as a mediator of confluence-dependent resistance to cell death induced by anticancer drugs. Cancer Res 1997:57: 2661-7.

Griffin MR, Bergstralh EJ, Coffey RJ, Beart RW, Melton LJ. Predictors of survival after curative resection of carcinoma of the colon and rectum. Cancer 1987;60:2318-24.

Hartl F, Hlodan R, Langer T. Molecular chaperones in protein folding: the art of avoiding sticky situations. Trends Biochem Sci 1994;19:20-5

Iino $\mathrm{H}$, Fukayama M, Maeda $\mathrm{Y}$, Koike M, Mori T, Takahashi T, et al. Molecular genetics for clinical management of colorectal carcinoma. Cancer 1994;73:1324-31.

Ito T, Kawabe R, Kurasono Y, Hara M, Kitamura H, Fujita K, et al. Expression of heat shock proteins in squamous cell carcinoma of the tongue: an immunohistochemical study. J Oral Pathol Med 1998; 27:18-22.

Lazaris AC, Theodoropoulos GE, Davaris PS, Panoussopoulos D, Nakopoulou L, Kittas C, et al. Heat shock protein 70 and HLA-DR molecular tissue expression. Prognostic implication in colorectal cancer. Dis Colon Rectum 1995;38;739-45.

Lu X, Seligy VLL. Hsp60/chaperonin gene expression and differentiation of human colon adenocarcinoma and multipotent leukaemic cells. Biochem Biophys Res Comm 1992;186:371-7.

Melis R, White R. Characterization of colonic polyps by two-dimensional gel electrophoresis. Electrophoresis 1999;20:1055-64.

Nitta Y, Suzuki K, Kohli Y, Fujiki N, Imamura Y, Noriki S, et al. Early progression stage of malignancy of human colon border-line adenoma as revealed by immunohistochemical demonstration of increased DNA-instability. Eur J Histochem 1993;37:207-18.

Rosai J. Ackerman's Surgical Pathology. Juan Rosai Edition: St. Louis; 1996. p. 729-50.

Sun XF, Zhang H, Carstensen J, Jansson A, Nordenskjold B. Heat shock protein $72 / 73$ in relation to cytoplasmic p53 expression and prognosis in colorectal adenocarcinomas. Int $J$ Cancer 1997;74: 600-4.

Tomlinson I, Ilyas M, Novelli M. Molecular genetics of colon cancer. Cancer and Metastasis Rev 1997;16:67-79.

Vendetti $S$, Cicconi $R$, Piselli $P$, Vismara $D$, Cassol $M$, Delpino A. Induction and membrane expression of heat shock proteins in heat treated HPC-4 cells is correlated with increased resistance to LAKmediated lysis. J Exp Clin Cancer Res 2000;19:329-34.

Zhang L, Pelech SL, Mayrand D, Grenier D, Heino J, Uitto VJ. Bacterial heat shock protein-60 increases epithelial cell proliferation through the ERK1/2 MAP kinases. Exp Cell Res 2001;266:1120. 
F. Cappello et al. 